\title{
On the linkage between hydrology and society-learning from history about two-way interactions for sustainable development
}

\author{
Saket Pande ${ }^{1} \cdot$ Stefan Uhlenbrook ${ }^{2,3}$
}

Received: 24 July 2018 / Accepted: 1 November 2020 / Published online: 17 November 2020

(c) The Author(s) 2020

\begin{abstract}
The challenge of sustainable development is enshrined in the ambitious 2030 Agenda for Sustainable Development of the United Nations. The 17 goals and its various targets are unique with water being one of the cross cutting themes. Taking examples of past water dependent societies in a comparative setting, this paper challenges the new field of Archaeo-hydrology in how it could contribute to the 2030 Agenda based on what can be learned from past and contemporary water dependent societies. We find that societies have coped with climate variability by diversifying both in occupation, livelihoods and use of space. Sharing the costs of coordinating such diversification requires inclusive institutions and technological innovations. Similar to technology, new social institutions emerge in response to a changing environment. However, in tandem, slow out-migration of people seems to go on, driven by better livelihood opportunities outside. If technological innovation and institutional evolution are not rapid enough, then migration seems to take over as the adaptive mechanism in response to environmental changes resulting in rapid dispersal. This means that migration from smaller, less endowed societies can be expected to be rapid, with repetitive cycles of abandonment and rehabilitation after each critical climate or adverse environment events. Consequently, more place based local innovations should be encouraged and local economies should be diversified to increase the resilience so that vulnerable societies may inherit favourable know-how for a sustainable future under changing climatic conditions.
\end{abstract}

Keywords Archaeo-hydrology · Diversification · Resilience $\cdot$ Migration · Indus valley civilization $\cdot$ Murrumbidgee river basin $\cdot$ Australia

Saket Pande

s.pande@tudelft.nl

1 Department of Water Management, Delft University of Technology, Stevinweg1, 2628CN Delft, The Netherlands

2 International Water Management Institute (IWMI), 127 Sunil Mawatha, Pelawatte, Battaramulla, Colombo, Sri Lanka

3 IHE-Delft, Westvest 7, Delft, The Netherlands 


\section{Motivation: achieving sustainable goals}

Tremendous progress in improving the human condition has been made as a result of the Millennium Development Goals. However, several challenges still remain. For example, the number of people living on less than $\$ 1.25$ a day has been reduced from 1.9 billion in 1990 to 836 million in 2015 (UN 2015). The Sustainable Development Goals of the Agenda 2030, set up with the ambition of continuing the progress, have 17 new goals and associated 169 targets. These goals have been inspired by three dimensions of sustainability: economic growth, environmental health, and social equity and development, both in the short and long run. As a result, there are several interlinked goals that are either in synergy with each other or potentially are in conflict, which makes the understanding of trade-offs very important for effective policy and decision making.

Understanding these interlinkages is thus critical in effective implementation of sustainable development goals (UN 2018). The above example exemplifies the interlinkages and hints at possible mechanisms of potential interlinkages. The understanding of such mechanisms then can guide practitioners on how to leverage on the synergies between the goals and on how to avoid the conflicts. Poverty alleviation, food security and economic growth are linked through employment, while economic growth and food security can be at conflict with environmental issues through water and environmental degradation. Clearly, water availability fosters growth which in turn, if not managed sustainably, can reduce water quality and quantity.

The productive use of water for food production and economic growth is therefore often in tension with restorative value of water for eco-system regeneration and functioning. This balance or imbalance between the two forces determines how sustainable a system is. For example, if the productive use of water for agriculture production dominates other uses of water, less water may be left available for the environment downstream, possibly leading to problem such as salt intrusion, excessive nutrient loading into our seas and loss of biodiversity as a result of degradation of wetland and other ecosystems.

Such imbalances have been observed in many basins, such as the Aral Sea in Central Asia and the Murrumbidgee river basin in Australia. The Aral Sea has witnessed significant drying from the 1960s to the present as a result of uninhibited water extractions from contributing rivers for cotton production. Despite of environmental deterioration and its direct health impacts, this desiccation went unabated (White 2013). On the other hand, the Murrumbidgee river basin, though witnessing similar pressure of productive forces, was successively able to restore the balance (Kandasamy et al. 2014). So, why is one different from the other and seems to have suffered a different fate? Is such temporal evolution of strongly water dependent societies similar to those in the past? Can we reaffirm the observations of contemporary basins and lessons learned from those of the past?

This paper argues that lessons of sustainable development can be learned from the evolution-for example rise and dispersal — of water based societies. We argue that lessons can be learned by comparing across societies, from ancient to contemporary ones, to highlight plausible mechanisms behind the rise and dispersal of such societies.

We have already stated our larger motivation: the attainment of the sustainable goals set out by the UN (Sect. 1). Next, we move to a theoretical discussion in which we outline what we mean by a comparative approach (Sect. "Need for comparative assessment"). In Sect. 3, we present two examples: the Indus River Basin (Sect. "The Indus river basin”) and the Murrumbidgee River Basin (Sect. "The Murrumbidgee river basin"). We then present the differences between the two cases and the obstacles these present to our comparative 
approach (Sect. "Differences between the Indus and the Murrumbidgee case studies"). Having addressed these differences, we assemble in Sect. "Dynamics common to both the case studies" a dynamic model that we believe applies to both cases. In Sect. "Generalization: legacy of past technological innovations", we present a generalization of this dynamic model, and argue for its applicability more widely based on a theory of technological pathdependence. In Sect. "Conclusions and implications for contemporary water policy", we return to the original motivation, and draw implications from this model for policies that can support these sustainable goals.

\section{Need for comparative assessment}

By following a comparative approach, we challenge the new field of archaeo-hydrology to facilitate comparison of historical and archaeological chronologies of diverse water based societies and delineate dominant mechanisms underlying the evolution of its institutions, economic well-being, environmental health and social equity-that can then be used to develop useful tools for recreating the past and predicting the future (Guedes et al. 2016). This can be one potential contribution of archaeo-hydrology to the current debate on sustainable development.

While water history and archaeology tend to be site-specific, several recent studies have highlighted how comparison of diverse societies can reveal interesting insights, for example on variation among societal types (Peregrine 2004) and even testing of hypotheses such as the critical role of inclusive institutions regarding climate resilience of ancient societies (Peregrine 2017). As Feinman (2012) argues, issues such as "what factors and conditions historically have engendered human societies to rise, fall, and reorganize" are not only critical for understanding our history, but also to evaluate the shifting political economy of today. Yet, these issues remain to be addressed more frequently in cognate disciplines such as history and sociology. While these disciplines study shifts in socio-economic situations in the past and theorize about its change based on site specific case studies, they often remain averse to learn from comparative analysis of diverse societies (Feinman 2012).

Economic theory on the other hand provides a rich theoretical foundation for interpreting patterns that are common across case studies in a comparative setting (Acemoglu and Robinson 2012). It does so by abstracting patterns across case studies and building a generic understanding of societal evolution, e.g. based on concepts of river games that view sharing of a river as a game between associated agents (Ambec and Sprumont 2000; van der Brink et al. 2012). Such river game models go beyond seeking correlations in data by using the models to decode the correlations. Yet another example is the theory of endogenous growth (Romer 1990) that suggests that technological innovation depends on past economic progress and demand for future innovation. This makes the co-evolution of coupled human-water systems dependent on the paths taken by societies, such as riches generated by cooperation with others through trade or collapse of societies due to overconsumption of resources.

Indeed, basins from the past and the present are different in terms of time periods, time spans and climatic boundary conditions, to the extent that one may even say that all system parameters and variables have been randomized for the object of the study (i.e. the basin). But this is the strength of a comparative set up. If a common (i.e. generalizable) pattern, e.g. of rise and dispersal of societies, is the only constant in the randomized setting, then the underlying mechanisms of such a pattern can be interpreted in terms of some consistent 
patterns of human behaviour that either create or respond to changing environmental conditions. Against this background, the merits of environmental determinism, path dependency and the importance of critical junctures in the evolution of coupled human water systems can be determined (Acemoglu and Robinson 2012).

Motivated by the need to delineate dominant mechanisms underlying the evolution of institutions, economic well-being and environmental health to inform the current debate on sustainable development, this paper sets out comparing a historical and a contemporary society, i.e. the Indus valley civilization and the Murrumbidgee River Basin respectively. The central hypothesis is that a generalized pattern of rise, fall and reorganization emerges from the imbalance between the two counteracting economic forces of demand and supply. As a result, statements about the role of interactions between hydrology and society in the rise and dispersal of societies and its policy implications for local to regional sustainable development are formulated.

\section{The Indus river basin}

The Indus river basin civilization emerged from isolated settlements along various tributaries of the Indus river (now in Pakistan and India). The earliest settlements were reported dating back to the beginning of the Holocene, in locations such as in Mehrgarh (Pakistan) around 9000 BP (Kenoyer 2011). The stabilization of temperature in the Holocene meant that migration, which has been an adaptive mechanism to cope with changing climate, was no longer required. These settlements slowly grew into larger settlements, into bigger towns and cities that rapidly connected through trade. During its peak, major cities centers of Harappa and Mohanjo-Daro emerged and the Indus valley almost became a quasi-state. The dispersal of the civilization that followed did not decimate the population of the basin; instead, pockets of settlements around major cities remained. Further, the out-migrating population kept its culture and tradition and laid seeds to other traditions, such as the IndoGangetic and Deccan traditions.

What is unique about the Indus Valley civilization is that its dispersal occurred around the time of a major drying event approximately 4200 years back. As Fig. 1 with paeleodischarge at the mouth of Indus shows, the drying event took nearly 700 years. Counter intuitively, the Indus Valley tradition matured, during the so-called Mature Harappa phase (see Fig. 1), in this period of drying, when the economy boomed and water-related technologies grew. This is counter-intuitive, as increasing scarcity is expected to negatively influence the development of a basin. For example, climate variability in late Holocene led to changes in subsistence strategy and outmigration in the West Liao River Basin, Northeast China (Jia et al. 2016). The Maya collapse has also often being attributed to the onset of a mega-drought that led to up to $40 \%$ reduction in water availability (Medina-Elizalde and Rohling 2012). Pande and Ertsen (2014) hypothesized that increased overall water scarcity led to increased cooperation throughout the Indus basin in terms of trade and within-basin migration of people. This allowed the population to diversify agricultural risk and flourish in spite of dwindling water supply, as has also been hypothesised for other ancient societies (Riel et al. 2014). Trade with the outside world accelerated and brought with it new traditions and people. These interactions led to more uniform cultural practices throughout the basin, yielding the tradition its identity of quasi-statehood (Kenoyer 2006).

Rainfall proxies for the winter rain and summer monsoons in the Indus river basin provides some insights into what happened during the 750 years period of Indus drying. As Fig. 2 shows, the winter rain serves the northern part of the basin, while the summer 


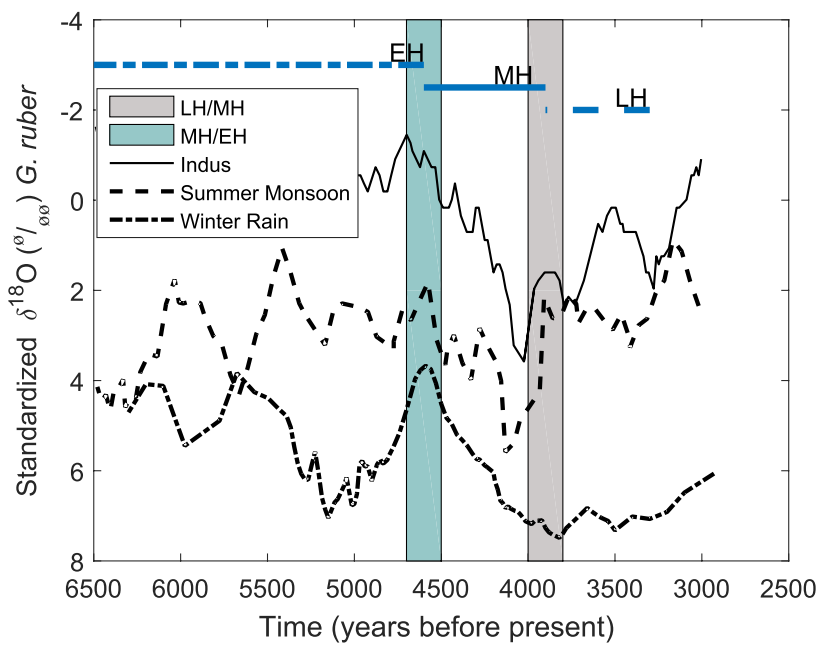

Fig. 1 Standardized (subtracting a time series by its mean and dividing it by its standard deviation) paleoclimatic proxies of the Indus river flow (Staubwasser et al. 2003), the summer monsoon (Stott 2008) and the winter rain (Bar-Matthews et al. 2003) during the rise and dispersal of Indus valley civilization. Higher $\delta^{18} \mathrm{O}$ values indicate warmer conditions and lesser rainfall. $L H$ Late Harappa period, $M H$ Mature Harappa period, and $E H$ Early Harrapa period. Note that Indus paleodischarge declined almost 5 standard deviations during the Mature Harappa period that lasted around 700 years. Figure adapted from Pande and Ertsen (2014)

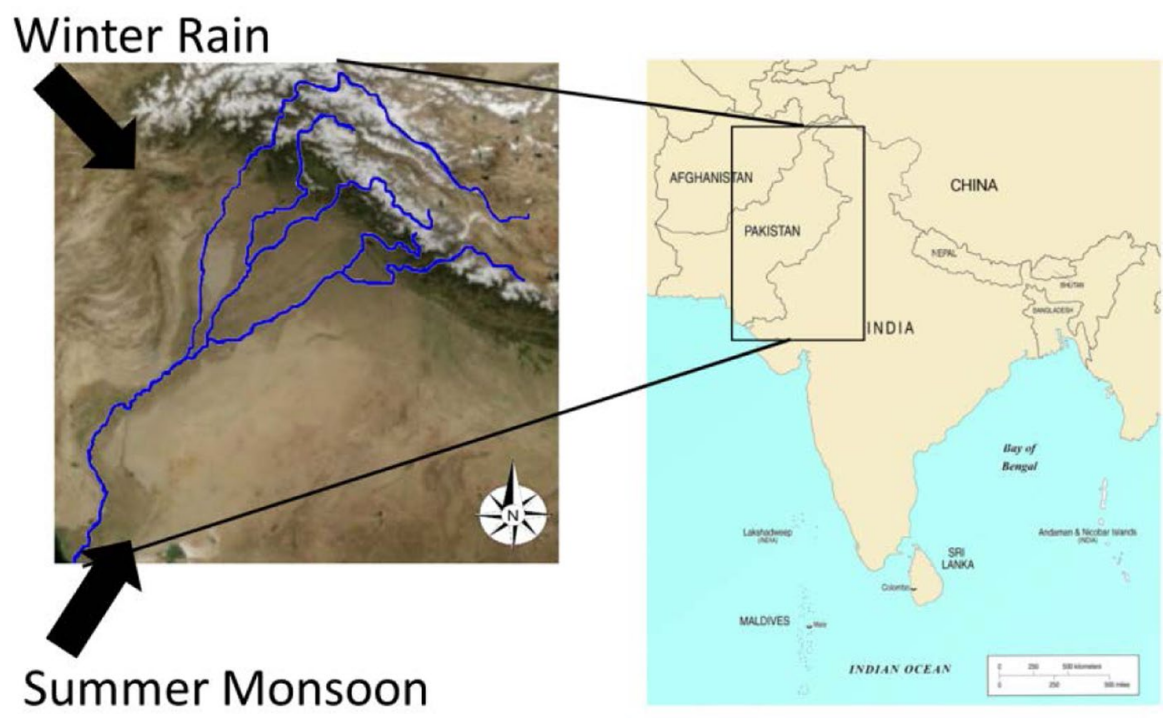

Fig. 2 An illustration of spatial distribution of summer monsoon and winter rain over the Indus river basin, located in South Asia, that generate stream flow at the outlet of the basin

monsoon mostly serves the southern part. Since winter rain also occurs as snow in high altitudes in the north, winter rains are an important source of melt water runoff in early spring the following year. Further, the Indus river and its tributaries flow from north to 
south. This makes summer monsoons crucial for southern parts, because with weak monsoons the population in the south are at the mercy of the water users upstream.

The decline in Indus streamflow was marked by consistent decline in water brought by winter rains. The summer monsoon instead weakened drastically towards 4200 BP. Thus, in the beginning of the mature phase, there was less need for cooperation between the north and the south, given the relative abundance of water in the south. However, towards 4200 BP, water became relatively scarcer in the south due to a sudden weakening of the summer monsoon. Using game theoretic concepts (Ambec and Sprumont 2000), Pande and Ertsen (2014) suggested that this created perfect conditions to cooperate in terms of trade and specialization, instead of migrating out as one would imagine as a response to an aridity shock. The eastern parts cultivated summer crops, while the north and the north-eastern parts specialized in winter crops (Madella and Fuller 2006). Evidence of increased water management and control structure not only indicate the need to use water more efficiently, but also demonstrates that society was able to find surpluses to invest in the development of human capital, such as water engineering skills (Bisht 2001). This technology-fuelled economic and consequently population growth gave way, when human needs per capita exceeded the carrying capacity, leading to a dispersal of people to different parts of the Indian subcontinent.

\section{The Murrumbidgee river basin}

The Murrumbidgee river basin (Australia) is a comparatively young basin in terms of population numbers. The basin, with its river flowing through traditional lands of Aboriginal tribes such as the Ngarigo, Ngunnawal, Wiradjuri, Nari Nari and Muthi Muthi, started to be inhabited at larger scale in late 1800s by European settlers for productive purposes. Often of British decent, these settlers were imbued with Victorian values of individualism and profit maximization. Water began to be used for agricultural production for private profit, which in turn fuelled population growth within the basin, mostly driven by migration of settlers from outside seeking better livelihoods. Increasing wealth within the basin further fuelled technological innovation-based agricultural production (Kandasamy et al. 2014).

The momentum of economic growth, individual well-being and technological growth meant that basin inhabitants felt being on top of nature. The early 1900s saw a rapid expansion of water storage capacities. The water stored in the reservoirs was increasingly diverted for irrigated agriculture, resulting in increased consumptive use in the form evaporation of water that otherwise could have been used by wetlands downstream for ecological consumptive use. Improved irrigation technology such as drip irrigation facilities meant that more crops could be grown per drop (Roobavannan et al. 2017a). This created the perception of abundance, attracting ever more people to the basin, as well as accelerating the within-basin natural growth rate.

Before the inhabitants could realize, the reduced river flow downstream resulted in contraction of wetlands that were home to its typical fauna. Also, water used for irrigation brought salinity with it, as the groundwater tables rose with irrigation. With more water storage capacity first being built downstream, communities started to emerge upstream along the river network, closer to the headwater where more storage capacity was developed. Community expansion upstream led to environmental degradation, making matters worse for the basin as a whole. The degradation continued to co-evolve with population 
growth within the basin, before finally being triggered to a shift in the relationship between the basin community and its water (Kandasamy et al. 2014).

A rigorous data analysis reveals that population decline was symptomatic of the change in water policy that reduced the amount of water being diverted to agriculture and increased the water allocated to the environment. The threshold moment was 1996, when the population within the basin dipped and the new policy was introduced. However, internal dynamics as interpreted by the socio-hydrological models on the dynamics reveal that the population was increasingly aware of degrading environmental conditions within the basin (Roobavannan et al. 2017a, b). This meant that the population took some time, witnessing green movements and media attention, before finally actions were taken to restore the environment. Till then, facilitated by technology to tackle environment degradation, such as fish steps and other artefacts to counter salinity, the population coped with environmental degradation.

When the policy finally changed, the basin witnessed not just a dispersal of people, who were 'pushed' out of the basin, but also a change in occupational choice of the farmers who were affected by policy-induced water scarcity for agriculture. Perhaps one of the strongest reasons why the Murrumbidgee river basin was able to navigate this policy change without much resistance from the local population was that the other, non-agricultural, sectors were growing fast (Roobavannan et al. 2017b). This provided alternate employment opportunities, making it easier for affected farmers to find new avenues to earn a livelihood. Those farmers who were able to cope with loss of income for some time, were able to expand their operations by buying out migrating farmers.

\section{Differences between the Indus and the Murrumbidgee case studies}

One dominant difference between the Murrumbidgee River Basin (MRB) and Indus valley civilizations is the intensity of anthropogenic activities. The Murrumbidgee evolution occurred in the era that is now famously dubbed as the Anthropocene. The rate of human settlement, the rate of water appropriation and the rate of crop production was very high. For example, the rate of population growth in the MRB was 600 people/year (Kandasamy et al. 2014). This was twice as high as the rate imputed for the Indus valley civilization based on archaeological evidence of human settlements and assumptions based on Vahia and Yadav (2011) (assuming an average settlement growth of 1.5 ha per year and an average urban population density of 200 people/ha). Note that the estimations for the Indus valley are conservative and may be at the higher end. Nonetheless, it shows that the MRB was populated at a higher rate, which was fuelled by water technology that allowed intense agriculture-at the cost of intense pollution.

Technology was not the only driver that allowed dense population settlement. Technology-enabled international trade further provided clear incentives to inhabitants in the MRB to shape their environment to their own benefit in the beginning. The Anthropocene also marked evolved political institutions, which accentuated the utilization of resourceshence the decadal temporal scale of Murrumbidgee's evolution from rise to its dispersal.

Settlement of the Indus Valley began in small pockets, e.g. Mehrgarh, with rudimentary hunter-gathering technology made out of stones. The locations of settlements were more driven by availability of water compared to contemporary societies such as the MRB, because their production technology was rudimentary, which did not allow them to locate within the basin more flexibly. Their movement was restricted, resulting from such low level of technology. 
The emergence of trading patterns within the Indus, which was resulting in the homogenization of its culture and norm-imparting its quasi-statehood identity-took centuries. It took time for the settlers of the Indus valley to utilize agricultural surplus for technological development, economic specialization and societal organization. Its low level of technology also prohibited intensification, which meant that farmers needed lot more land and water per unit of food grown - compared to the MRB. Low intensity therefore meant more distance between the settlements, meaning that more time was needed to initiate communication and trade between far-off settlements and trade.

Thus, low levels of technology, which in a way set settlers in the Indus Valley far apart, took time to endogenously evolve from surpluses generated from local/disconnected production activities along the Indus. Had the Indus settlers had current levels of agricultural technology, e.g. in present day Doabs, the intensity of activities and population growth would have been higher, with interactions happening more rapidly and at shorted spatial scales. This we indeed see in present day Pakistan and western India, where smaller subbasins of the Indus are getting ever more troubled by dwindling water tables and increasing salinity as a result of intensive irrigation.

Declining water availability due to reducing rainfall was at a centennial scale for the Indus Valley. In case of the MRB, water stress was not a result of a change in climate. The time scale of the coupled evolution of humans and basin in both the case studies was also different. The Indus Valley chronology spanned over 7500 years, while in the case of Murrumbidgee it spanned over 100 years. Also, we have more accurate documented evidence on what happened in the Murrumbidgee, including information about changing values with regards to water in popular news media. Indeed, cultural response to environmental change, either human-induced or extra-terrestrial (changes in solar irradiance), determined whether whole a civilization dispersed and its population diminished to much lower subsistence levels, such as the Indus dispersal, or populations migrated and adapted to new subsistence modes, such as in the more contemporary MRB (deMenocal 2001). The two case studies are not only different in terms of the time periods that they represent, but also in terms of the level of technology that they had and, as a result, the spatial and temporal scale over which the two societies operated.

\section{Dynamics common to both the case studies}

Despite the differences, the two basin societies share the boom-bust cycle of emergence and dispersal, or the exploitation-conservation-release cycle (Allcock 2017; Munoz et al. 2010). Allcock (2017) observed that the time scale of boom-bust cycles (that is how long the cycle reorganization $\rightarrow$ exploitation $\rightarrow$ conservation $\rightarrow$ release, took) of ancient societies in Turkey became shorter as the rupture periods moved closer to the present. The cultures and phases that followed Indus civilizations were also brief in comparison to the rise and dispersal of the Indus valley civilization itself (e.g. Gandhara grave culture that followed lasted for 1500 years; Kenoyer 2011). Similar patterns are observed for the riseto-dispersal time scale of the MRB, which is approximately 100 years-much shorter than the Indus valley civilization. Further evidence for such interpretations can be found in the chronology of the Indus valley civilization and contemporary datasets of MRB (Pande and Ertsen 2014; Kandasamy et al. 2014).

Figure 3 shows time plots of settled area (black line) alongside social complexity (blue) of the Indus Valley, based on Vahia and Yadav (2011). Both parameters increased in magnitude, as the tradition matured. The water technology co-evolved with social 


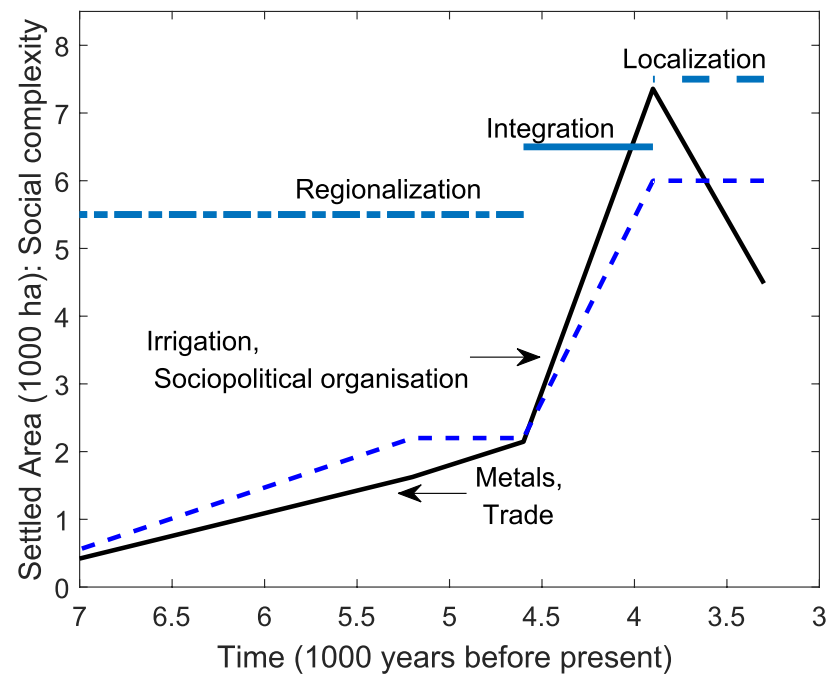

Fig. 3 Illustration of settled area (black lines) alongside social complexity (blue lines) based on Vahia and Yadav (2011) during the rise and dispersal of the Indus Valley civilization. Water management infrastructure and social political organization intensified during the drying period (4700-4200 years before present, see Fig. 1). The Integration period is the Mature Harappa phase, when the Indus Valley tradition emerged as a quasi-state. It was preceded by the period of Regionalization, during which trade links between different parts of the Indus valley basin developed. Integration was followed by the Localization period, which is when the civilization dispersed to other parts of South Asia and regionally disconnected local traditions emerged

complexity, as a result of past surpluses, in terms of wealth and human capital, that were invested back into growth and technological development. However, as social complexity increased in terms of expanded network of trade within the Indus, the overhead costs to coordinate became more than the surplus that was generated. This weakened the harmony between demand pull and the supply push, as the latter started to lag behind. The persistent drying of the climate added to the perils of increasing urbanization and an expanding trade network, which then led to eventual dispersal. As the major cities depopulated, lack of labor meant deteriorating water management infrastructure, further reducing the carrying capacity and accelerating the depopulation of the region.

Figure 4 plots the evolution of storage capacity in MRB over time, overlaid with a smoothed line (as shown in the inset). The smoothed line is similar to the illustrative curve of the evolution of water institutions in the Indus valley in Fig. 3. Both appear to be 'S' or logistic-shaped curves. Such curves can be interpreted as a symptom of endogenous, path dependent, technological growth and a reflection of society's heritage. In the beginning, the demand pull for technological growth is weak. As a result, the curve is relatively flat. A similar flat part is at the higher end of the curve, but here the supply push is weak due to expanding overheads of a fast growing society and corresponds to upcoming population dispersal. The connecting part between the two flat parts of the $S$ curve develops when demand pull is in harmony with supply push-similar to the interpretation of the friction between productive forces and restorative forces in the MRB by Roobavannan et al. (2017a). 


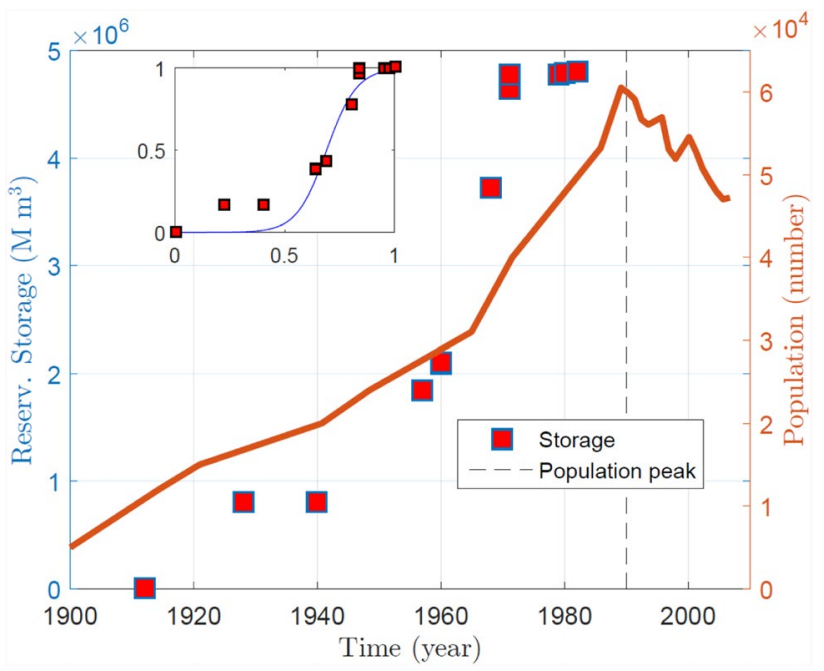

Fig. 4 Evolution of total water storage capacity of major dams (as a proxy of production enabling technology) and population in the Murrumbidgee river basin, Australia. The inset figure shows the same water storage capacity time series, scaled between 0 and 1 with a best-fit $S$ shaped function (in blue). Technology followed an S shaped curve, that flattened out before the population peaked around 1990 in the Murrumbidgee river basin

The differences in scale and technologies of the two societies is then reflected in the slope or steepness of the middle part of the technological ' $S$ ' curve. This can be interpreted as an emergent property of how hydro-climatic and other conditions, such as soil fertility, facilitated economic production, surplus generation and technological innovation or adoption. A landscape with poor soil and water availability conditions is likely to produce less surplus, thereby resulting in a technological S curve that may have a shorter and flatter rising part.

The mechanisms behind the transition from the synergetic pull-push part of the ' $S$ ' curve to the flat part may further be inferred, based on media records in case of MRB (Roobavannan et al. 2018) and archaeological evidence in case of the Indus (Kenoyer 2005). In the case of MRB, it is well documented that environmental degradation, which came along with technological innovation, led to community-wide dissatisfaction with the state of the environment (Roobavannan et al. 2018). This triggered changes in water use policy that consequently led to structural change in the basin wide economy, i.e. agricultural sector shrank and water independent industry sector expanded. Farmers migrated either to other locations outside the basin or other occupations within the basin. In the case of the Indus, archaeological evidence suggests that the transition from the rising part to the flat part of the technological S-curve (Fig. 3) likely happened alongside weakening trade links between late Harappan settlements (Kenoyer 2005). The settlements sustained themselves through local production by migrating to fertile areas in the eastern Punjab, northern Rajasthan and Haryana areas, and to the Indo-gangetic plains, or by migrating to specialized farming practices of intensive cultivation of crops permitted by local rainfall.

The Indus Valley civilization dispersed after a sharp decline in Indus discharge, resulting from weakened summer monsoon and winter rain. This was not the case for MRB, though it did witness the millennium drought between 2001 and 2010. The MRB was already changing its water policy in the mid-1990s, in response to decades of environmental 
degradation caused by water abstractions for agriculture. Yet, the effect on the population movement was similar, i.e. dispersal. As such, both basins witnessed swings of population and development of settlements in terms of a rising population and surplus being generated, followed by eventual dispersal. These features of co-evolution are the subjective matter of comparative analysis of water-dependent societies from both past and present (Feinman 2012; Peregrine 2004).

An extension of such dynamic conceptualization to other societies is presented in the following section, founded on economic theory and quantitative social sciences that rigorously seek generalizable patterns across case studies. This sacrifices more place-based information for the sake of abstraction at a higher level. Historical narratives instead are used to validate predictions of models based on abstracted generalized understanding. While the comparative approach proposed here is in tune with the need of archaeo-hydrology to be more based on the method of scientific inquiry (like in hydrology), it may not be compatible with concepts from the humanities, such as history, that may view evolution as resulting from a series of events that are independent of the evolutionary path taken in the past. A common way forward in conceptualizing the human past may indeed be that the evolutionary path is neither entirely dependent on the path that it has taken in the past, nor that it resulted from a series of accidents beyond the control of the agents concerned, but that it was a combination of both.

\section{Generalization: legacy of past technological innovations}

Evolution of water-scarce societies may be conceptualized as a co-evolutionary process, resulting in path dependencies that emerges from endogenous change in technology. Often, such paths are perturbed at critical junctures that shock the dynamics to other states, begetting another dynamic based on the creative destruction of prior achievements. If technological evolution were a completely random process, meaning that any society at any point in time randomly achieves a high level of technology independent of the technology it inherited from the past, then spatial and temporal scales of basin scale rise and dispersal of population would also be random. The $\mathrm{S}$ curve will then not be an emergent property of the coevolution. This may then also mean that the observed rise and dispersal of small scale societies, such as the Murrumbidgee, can occur at millennial time (and vice versa for the large scale Indus Valley). However, the spatio-temporal scales of the water dependent societies appears to become smaller over time. As the scales become finer with time, or in other words as the interactions intensified with time as represented by the steepness of the middle part of the $\mathrm{S}$ curve, the societies rise and disperse at shorter spatial and temporal scales-as observed in the case of the Indus and the Murrumbidgee. There are other examples to further support such arguments. The Maya and the Mesopotamian civilizations rose and dispersed at regional and millennial time scales (deMenocal 2001; Webster et al. 2007; Douglas et al. 2015), while the more recent Hohokam (Waters 2008; Purdue and Berger 2015) and Cahokia societies (Munoz et al. 2015), in Arizona and Mississippi respectively, rose and dispersed at more local, sub-basins scale at centennial time scale. In this paper, we restrict ourselves to the Indus and MRB case studies when viewing water-based societies through the lens of endogenous growth theory.

Endogenous growth theory proposes that technological advancement is not a random sequence of historical events, but a consequence of past technological development is (Romer 1990; Pande et al. 2014). The theory suggests that technology is like other goods, 
such as food, that an economy produces. It needs capital, e.g. money, labor, e.g. scientists as skilled labor who produce new knowledge, as inputs and past technological knowhow to further advance technology. Thus, inheritance of technology developed, adopted or adapted by past generations, plays an important role in producing new technologies and distinguishes one society from another. However, the production of technology is hindered when either the availability of capital or labor is scarce or when application of technology does not yield the returns that are desirable for it to be an attractive investment of capital and labor.

Technological innovation, and the corresponding S curve, thus emerges due to an interplay between push and pull factors. Not only should there be societal need for technological advancement ('pull'), but society should also be at a certain level of specialization, efficiency and well-being to have enough surplus to afford such a technological innovation ('push'). In the beginning of societal development, demand for technological innovation may be low due low population pressure and hence less need to produce food efficiently, if there is enough water available. With increasing population and increasing stress on resources, the demand to produce efficiently often increases. However, the society may only be able to 'push' much needed innovation, if the society is specialized enough and is able to save enough.

Technological development appears to be no guarantee for uninterrupted growth. Stronger technological development may at best delay the peak of population or economic growth, since planetary boundaries of essential ingredients of growth such as water and minerals limit growth (Steffen et al. 2015). Nonetheless, changes in water management norms and related institutions and hence behaviour induced by scarcity induced, i.e. endogenous water policy change, are important aspects of coupled human-water systems at basin scales. Past societal evolution appears to play an important role by facilitating or obstructing appropriate adaptation pathways for the future. The strong institutions of the MRB reduced and even reversed the effect of anthropogenic water use. Its inclusive institutions safeguarded the health and wellbeing of current and future generations of its inhabitants, allowing a more sustainable future (in context of ancient societies see Peregrine 2017).

Since technological and institutional development of a society depends on the past, it depends on the initial condition at the start. How a society begins to develop and the scale to which it is able to expand, determines how resilient it becomes and how much more it can develop further in terms of technology and resilience to exogenous influence, such as climatic changes. This is to say that technological and institutional capital that a society is gifted with, to a certain extent determines what it can achieve in the future. For example, small-scale societies, such as Cahokia (Munoz et al. 2015) and settlements in the coastal deserts of Peru (Dillehay and Kolata 2004; Sandweiss et al. 2009), could only afford smallscale infrastructures. As a result, they were forced to migrate and resettle during moderately severe drought events. Larger scale civilizations were able to comparatively cope with protracted drying conditions a lot longer.

Migration to more suitable locations, to less water-dependent occupation or to more intensive agriculture, appears to be a natural response to gradients in livelihood opportunities, such as in the case of MRB (Roobavannan et al. 2017a, b). Humans have often adapted to changes through such mechanisms, especially when adaptation strategies designed for anticipated (sets of) events fail. The Indus valley civilization was primarily an agrarian society with livelihood opportunities mostly dependent on water. Migration was likely driven by a gradient with respect to water productivity (Kenoyer 2006), perhaps because of occupational specialization built up from the past. That is, humans may have migrated to agricultural activities that could still be maintained at lower amounts of water or to 
locations where water was abundant. However, this was not the case for MRB, where the economy was more diversified. Hence, migration mostly happened to other employment opportunities not necessarily linked to water (Roobavannan et al. 2017a). The migration was driven by a gradient in employment opportunities, such as that in manufacturing and services sectors, and was not driven by the gradient in water availability. Farmers who gave up farming in the Murrumbidgee did not settle in other river basins, but instead picked up other jobs. Strong performance of other economic sectors diversified the agricultural risk.

Over time, faster cycles of boom and bust of ancient societies have been observed (Allcock 2017; Munoz et al. 2010). This likely means that technology enabled not only more efficient appropriation of water resource for agricultural production and societal development, but also more rapid use of it. This paradoxically led to more rapid population growth and faster approaching of unsustainable limits of water use. Here, the scale and initial level of wealth of a water-dependent society appears to be an important consideration, because such aspects affect how a society accumulates wealth, adopts or innovates new technology and adapt to variability by migrating out, if water technology is not enough. The settlement and out-migration cycle of the MRB has been rapid compared to the dispersal of the Indus.

\section{Conclusions and implications for contemporary water policy}

Societies have coped with climate variability by diversifying both in occupation/livelihoods and use of space. They have moved from intensive agriculture to more trade based poly-centric governance structure in response to climate variability. Such a pattern is not surprising, since humans are driven by the need for stability (Peregrine 2017). However, it costs to coordinate diverse human activities. For example, rules and norms under which trade occurs, require policing and strong governance. Therefore, stable institutions are not possible if local economies do not perform well enough and generate sufficient surplus to pay for the cost of coordinating and regulating activities within a society. The adaptive shift from autarkic (isolated) pockets to a more trade based society, that brings different parts of the society together, therefore requires a strong economy that can generate sufficient surplus to pay for the governance related costs (i.e. law enforcement, judicial system etc.).

The comparative analysis of an ancient and a contemporary society in the paper suggests that technological innovation needed to grow an economy efficiently, in order to generate sufficient surplus, is often driven by the demands of a changing climate and a growing population. Similar to technology, new social institutions emerge in response to the changing environment. The emergent technology and institutions then become part of a society's heritage. If technological innovation and institutional evolution are not rapid enough, then migration can take over as the adaptive mechanism in response to environmental changes resulting in dispersal. Otherwise, the interplay between technology-fuelled economic growth and slow migration delays the eventual dispersal, until the carrying capacity can no longer cope with growing demands of changing demography and climate. This is what has been observed in the Murrumbidgee river basin and what archaeological evidence suggests for the Indus river basin. Further, if a society is endowed with limited technology and weak institutions to begin with, it may witnesses rapid cycles of migration in and out of its domain.

Migration is one key adaptive mechanism of societies, when faced with change and ineffective or insufficient technological advancement for coping with changing conditions. People in rich, resilient societies are less prone to migration. Poorer, less developed and 
less resilient communities seem to have more frequent migrations. Second, the "boombust" cycles are not only more rapid in smaller scale societies, but these cycles repeat more often too. This means that migration from such smaller, less endowed, societies are also expected to be rapid, with repetitive cycles of abandonment and rehabilitation after each critical climate or adverse environment event.

Based on these observations, the following policy implications can be synthesized that are of relevance to sustainable development:

- Encourage place-based technological innovations and sustainable, adaptive climate optimal farming practices: such intervention will positively nudge local development to produce agriculturally more efficiently and sustainably.

- Diversify local economies and consequently occupational and livelihood opportunities, especially in those societies that are more prone to climate variability and environmental change. This will increase resilience to change and abate migration flows by empowering the population with the option of being employed in economic activities that are less dependent on water and natural resources.

- Raise awareness that water related technological innovation is not a 'silver bullet' and can only delay consequences of rising population and untethered economic growth. Technology is a means to an end and will not necessarily enable people to addresses the root causes of crises, such as water pollution and waste; however, technologies can remedy its negative effects up to a certain level.

- Engage all affected stakeholders in decision making for resilient adaptation to changing climatic and other environmental conditions: inclusive policy making produces options that considers different perspectives and is more likely to be accepted and effective.

These first policy conclusions are based on a synthesis of a limited number of societies. Future studies can be more organized and rigorous in drawing conclusions from a comparative project on current and ancient societies of relevance to policy making.

Acknowledgements The authors are grateful to the two referees and the editor Maurits W. Ertsen for their critical review of the manuscript. Thanks are due to Sumit Meshram for providing Fig. 2.

Open Access This article is licensed under a Creative Commons Attribution 4.0 International License, which permits use, sharing, adaptation, distribution and reproduction in any medium or format, as long as you give appropriate credit to the original author(s) and the source, provide a link to the Creative Commons licence, and indicate if changes were made. The images or other third party material in this article are included in the article's Creative Commons licence, unless indicated otherwise in a credit line to the material. If material is not included in the article's Creative Commons licence and your intended use is not permitted by statutory regulation or exceeds the permitted use, you will need to obtain permission directly from the copyright holder. To view a copy of this licence, visit http://creativecommons.org/licenses/by/4.0/.

\section{References}

Acemoglu D, Robinson J (2012) Why nations fail. Crown Publishing Group, 546pp, ISBN: 0307719219.

Allcock SL (2017) Long-term socio-environmental dynamics and adaptive cycles in Cappadocia, Turkey during the Holocene. Quatern Int 446:66-82

Ambec, S. and Y. Sprumont (2000). Sharing a river. Cahier de recherché du GREEN 00-06.

Bar-Matthews M, Ayalon A., Gilmour M, Matthews A., Hawkesworth CJ (2003) Soreq and Peqiin Caves, Israel Speleothem Stable Isotope Data, IGBP PAGES/World Data Center for Paleoclimatology Data Contribution Series \#2003-061, NOAA/NGDC Paleoclimatology Program, Boulder CO, USA 
Bisht RS (2001) The water structures and engineering of the Harappans at Dholavira (India). In: Jarrige C, Lefevre V (eds) South Asian Archaeology 2001, vol. 1, Proceedings of the Sixteenth International Conference of teh European Association of South Asian Archaeologists, 2-6 July, 2001

DeMenocal PB (2001) Cultural responses to climate change during the Late Holocene. Science 292:667-672

Dillehay TD, Kolata AL (2004) Long-term human response to uncertain environmental conditions in the Andes. PNAS 101(12):4325-4330

Douglas PMJ, Pagani M, Canuto MA, Brenner M, Hodell DA, Eglintone TI, Curtis JH (2015) Drought, agricultural adaptation, and socio-political collapse in the Maya Lowlands. PNAS 112(18):5607-5612

Feinman, G. M. (2012). Comparative frames of the diachronic analysis of complex societies: Next steps. In: Chapter 3: The comparative Archaeology of complex societies, Ed. M.E. Smith, 21-43, Cambridge University Press.

Guedes JA, Crabtreea SA, Bocinsky RK, Kohlera TA (2016) Twenty-first century approaches to ancient problems: climate and society. PNAS 113(51):14483-14491

Jia X, Sun Y, Wang L, Sun W, Zhao Z, Lee HF, Huang W, Wu S, Lu H (2016) The transition of human subsistence strategies in relation to climate change during the Bronze Age in the West Liao River Basin, Northeast China. The Holocene 26(5):781-789

Kandasamy J, Sounthararajah D, Sivabalan P, Chanan A, Vigneswaran S, Sivapalan M (2014) Sociohydrologic drivers of the Pendulum Swing between agriculture development and environmental health: a case study from Murrumbidgee River Basin, Australia. Hydrol Earth Syst Sci 18:1027-1041

Kenoyer, M. J. (2005). Bead Technologies at Harappa, 3300-1900 BC: A comparative summary, in: South Asian Archaeology 2001, edited by: Jarrige, C. and Lefèvre, V., Paris, Editions Recherche sur les Civilisations -ADPF.

Kenoyer MJ (2006) Cultures and societies of the indus tradition. In: Thapar R (ed) Historical roots in the making of "the Aryan." National Book Trust, New Delhi, pp 21-49

Kenoyer MJ (2011) Changing perspectives of the Indus Civilization: new discoveries and challenges. Puratattva 41:1-18

Madella M, Fuller DQ (2006) Palaeoecology and the harappan civilisation of south Asia: a reconsideration. Quat Sci Rev 25:1283-1301

Medina-Elizalde M, Rohling EJ (2012) Collapse of Classic Maya Civilization related to modest reduction in precipitation. Science 335:956-959

Munoz SE, Gajewski K, Peros MC (2010) Synchronous environmental and cultural change in the prehistory of the northeastern United States. PNAS 107(51):22008-22013

Munoz SE, Gruley KE, Massie A, Fike DA, Schroeder S, Williams JW (2015) Cahokia's emergence and decline coincided with shifts of flood frequency on the Mississippi River. PNAS. https://doi. org/10.1073/pnas.1501904112

Pande S, Ertsen MW (2014) Endogenous change: on cooperation and water in ancient history. Hydrol Earth Syst Sci 18:1745-1760

Pande S, Ertsen MW, Sivapalan M (2014) Endogenous technological and population change under increasing water scarcity. Hydrol Earth Syst Sci 18:3239-3258

Peregrine PN (2004) Cross-cultural approaches in Archaeology: comparative ethnology, comparative archaeology, and archaeoethnology. J Archaeol Res 12(3):281-309

Peregrine PN (2017) Social resilience to climate-related disasters in ancient societies: a test of two hypotheses. Weather, Climate and Society

Purdue L, Berger J-F (2015) integrated socio-environmental approach to the study of ancient water systems: the case of prehistoric Hohokam irrigation systems in semi-arid central Arizona, USA. J Archaeol Sci 53:586-603

Riel S, Pustovoytov K, Weippert H, Klett S, Hole F (2014) Drought stress variability in ancient Near Eastern agricultural systems evidenced by $\delta 13 \mathrm{C}$ in barley grain. PNAS 111(34):12348-12353

Romer PM (1990) Endogenous technological change. J Political Econ 98:S71-102

Roobavannan M, Kandasamy J, Pande S, Vigneswaran S, Sivapalan M (2017a) Role of sectoral transformation in the evolution of water management norms in agricultural catchments: a socio-hydrologic modeling analysis. Water Resour Res 53:8344-8365. https://doi.org/10.1002/2017WR020671

Roobavannan M, Kandasamy J, Pande S, Vigneswaran S, Sivapalan M (2017b) Allocating environmental water and impact on basin unemployment: Role of a diversified economy. Ecol Econ 136:178-188

Roobavannan M, van Emmerik THM, Elshafei Y, Kandasamy J, Sanderson MR, Vigneswaran S, Pande S, Sivapalan M (2018) Norms and values in sociohydrological models. Hydrol Earth Syst Sci 22:1337-1349

Sandweiss DH, Solís RS, Moseley ME, Keeferd DK, Ortloffe CR (2009) Environmental change and economic development in coastal Peru between 5,800 and 3,600 years ago. PNAS 106(5):1359-1363 
Staubwasser M, Sirocko F, Grootes PM, Segl M (2003) Climate change at the 4.2 ka BP termination of the Indus valley civilization and Holocene south Asian monsoon variability. Geophys Res Lett 30:1425. https://doi.org/10.1029/2002GL016822

Steffen W, Richardson K, Rockström J, Cornell SE, Fetzer I, Bennett EM, Biggs R, Carpenter SR, de Vries W, de Wit CA, Folke C, Gerten D, Heinke J, Mace GM, Persson LM, Ramanathan V, Reyers B, Sorlin S (2015) Planetary boundaries: guiding human development on a changing planet. Science 347(6223):1259855. https://doi.org/10.1126/science.1259855

Stott L (2008) Pacific Warm Pool MD98-2181 Late Pleistocene Foraminiferal SST Data. IGBP PAGES/ World Data Center for Paleoclimatology Data Contribution Series \# 2008-030, NOAA/NCDC Paleoclimatology Program, Boulder CO, USA

UN (United Nations) (2018) Sustainable development goal 6 synthesis report 2018 on water and sanitation. United Nations, New York, NY

UN (United Nations (2015) The millennium development goals report 20151. United Nations, New York, NY

Vahia MN, Yadav N (2011) Reconstructing the history of Harappan civilization. Soc Evol Hist 10(2)

Van der Brink R, van der Laan G, Moes N (2012) Fair agreements for sharing international rivers with multiple springs and externalities. J Environ Econ Manag 63:388-403

Waters MR (2008) Alluvial chronologies and archaeology of the Gila River drainage basin, Arizona. Geomorphology 101:332-341

Webster JW, Brook GA, Railsback LB, Cheng H, Edwards RL, Alexander C, Reeder PP (2007) Stalagmite evidence from Belize indicating significant droughts at the time of Preclassic Abandonment, the Maya Hiatus, and the Classic Maya collapse. Palaeogeogr Palaeoclimatol Palaeoecol 250:1-17

White K (2013) A geographical perspective on the Aral Sea crisis: three interpretations of an image. In: Szymanska D, Chodkowska-Miszczuk J (eds) Bulletin of geography. Socio-economic Series No. 21. Nicolaus Copernicus University Press, Torun, pp 125-132

Publisher's Note Springer Nature remains neutral with regard to jurisdictional claims in published maps and institutional affiliations. 